\title{
A Comparison of Forecasting Algorithms for Tsunami Detection with In-Situ Data
}

\author{
Tata Sudhakar ${ }^{1,3}$, C.D. Suriyakala ${ }^{2}$ \\ ${ }^{1}$ Research scholar, Sathyabama University, Sholinganallur, Chennai, Tamil Nadu 600119 \\ ${ }^{3}$ Scientist - F \& Head, Ocean Electronics Group, \\ National Institute of Ocean Technology, Pallikaranai, Chennai, 600100, INDIA \\ tata@niot.res.in \\ ${ }^{2}$ Professor \& Head of PG Studies (ECE),Toc H Institute of Science \& Technology, \\ Arakkunnam, Ernakulam, Kerala, India, Pin-682 313 \\ drcdsk@yahoo.in
}

\begin{abstract}
An undersea earthquake or a geological disturbance causes Tsunami. Initial attempts to forecast Tsunami was made in Hawaii in the 1920s. The National Oceanic and Atmospheric Administration (NOAA) has been operating Tsunami early warning systems (DART) since 1949 for the Pacific Ocean. An accurate prediction algorithm helps to detect even a small Tsunami. The NOAA predicts Tsunami using Newton's forward divided difference formula from measured pressure time series. In this article, we compare the performances of Kalman algorithm and Artificial Neural Network (ANN) algorithm with respect to NOAA Tsunami Early warning system using in-situ data. We also discuss statistical characteristics of these algorithms. The ANN and KALMAN algorithm detect Tsunami with equal delay with respect to DART algorithm. The overall percentage of error rate is less with ANN. This study shows ANN algorithm is the optimized alternate algorithm to detect Tsunami.
\end{abstract}

Keywords: Tsunami-detection algorithm; Real-time using BPR, Determination of co efficient

\section{INTRODUCTION}

The Tsunami is detected by Bottom Pressure Recorder (BPR) deployed in the deep sea. The first deep ocean detection system called DART (Deep-ocean Assessment and Reporting Tsunami) system is developed by Pacific Marine Environmental Laboratory (PMEL) of National Oceanic and Atmospheric Administration (NOAA), USA [1] in 1995. The system consists of a BPR to measure water levels in the Tsunami frequency band with 0.1 millimeter resolution. The BPR transmits information to a moored surface buoy through acoustic telemetry. The moored buoy transmits the information to shore station through satellite telemetry. A series of DART systems are deployed since 1991 to monitor Tsunami events.

The important features of Tsunami detection algorithms are number of samples required, accuracy and computation time. The BPR records a superposition of tidal wave, Tsunami wave and surface turbulence. The tides can be forecasted from in-situ measurements using algorithms [2]. The presence of Tsunami signal increases the difference between forecasted and measured pressure. Hence, an accurate prediction algorithm helps to detect even a small Tsunami. In this article we compare the performances of DART [4], Kalman and Artificial Neural Network algorithms with in-situ data.

\section{DATA AND METHODS}

The BPR system deployed in the deep sea, at a depth of 3793m, in the Bay of Bengal by NOAA (Buoy ID 23227, position, Lat. $6.255^{\circ} \mathrm{N}$ Lon. $88.792{ }^{\circ} \mathrm{E}$ ) provides the data (ranging from 2012 to 2014) studied for our analysis [3]. A Tsunami was generated by a Mw 8.6 earthquake $\left(2.327^{\circ} \mathrm{N}, 93.063^{\circ} \mathrm{E}\right)$, at $08: 38: 36 \mathrm{UTC}$ on 11 April,2012. In approximately 39 minutes after the event (at 09:17), the Tsunami wave was first recorded at DART buoy 23227. The BPR records data at every $15 \mathrm{sec}$. We studied 1400 samples of data $(5.83 \mathrm{hr}$ ) before the event, 1100 samples of data $(4.58 \mathrm{hr})$ during the event and 2389 samples of data $(9.95 \mathrm{hrs})$ after the event (Figure $1)$. 


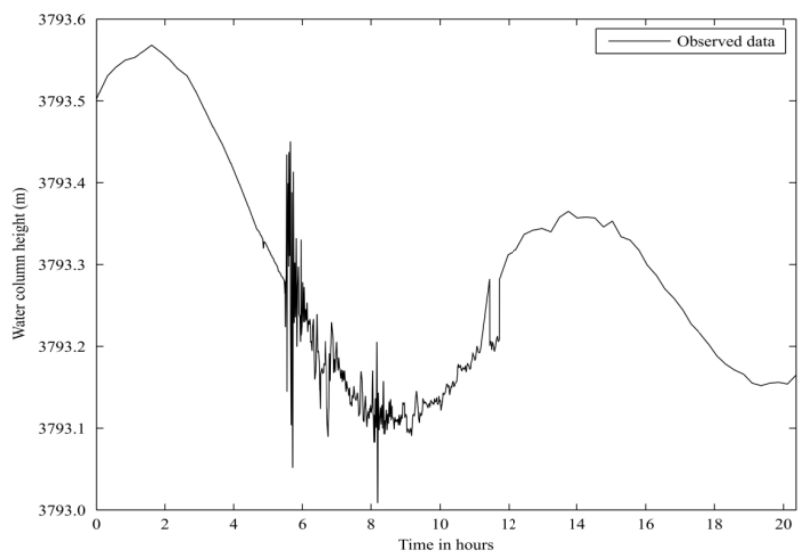

Fig.1. Observed data (courtesy: NOAA)

\section{A. DART prediction program}

The Tsunami-detection algorithm developed by Mofjeld under the DART prediction program predicts the pressure from 10 minute averaged measurements for $190 \mathrm{~min}$ [4] .

$H_{p}\left(t^{\prime}\right)=\sum_{i=0}^{3} w(i) H^{*}(t-i \times d t)$

Where the $H^{*}$ denotes 10-min averages; $d t=1 \mathrm{hr}$ and $H_{p}$ the predicted pressure. The prediction time $\mathrm{t}^{\prime}$ is set to 5.25 minutes, which is half the 10 minute averaging interval plus the 15 -second sampling interval for the BPR. The coefficients $w(i)$ are derived from Newton's formula (II) for forward extrapolation. Using these temporal parameters, the $w(i)$ coefficients are given in Equation (2-5).

$w(0)=1.16818457031250$

$w(1)=-0.28197558593750$

$w(2)=0.14689746093750$

$w(3)=-0.03310644531250$

A Tsunami is detected if the difference between the observed and the predicted pressure $H_{p}$ exceeds the detection threshold ( $0.03 \mathrm{~m}$ water column). The DART prediction program requires 760 samples (190 minutes of data).

\section{B. Kalman filter}

The Kalman filter [5-9] is a recursive algorithm which estimates an unknown variable from observations over a period. The algorithm consists of two steps [6][7]. In the first step, it produces an estimate of the current state variables along with their uncertainties; while in the next step, these parameters are updated with weighted average with more weight for the measurement with higher certainty. The priori estimation and error covariance are connected as the input parameter and predicted data is fed back to Gain Adjustment factor.

The project state ahead priori estimate is

$$
\hat{x}_{k}{ }^{-}=A \hat{x}_{k-1}+B u_{k-1}
$$

where $A$ and $B$ is state input matrix. The previous state time step is represented as $k-1$ and present time step is $k$.

The Error covairance is given as

$$
P_{k}^{-}=A P_{k-1} A^{T}+Q
$$

where $Q$ is the process noise covariance.

The gain of the filter is given by

$$
K_{k}=P_{k}^{-} H^{T}\left(H P_{k}^{-} H^{T}+R\right)^{-}
$$

where $H$ is state to measurement and $R$ is the measurement covairance.

The updated measurement is expressed as

$$
\hat{x}=\hat{x} K_{k}\left(z_{k}-H \hat{x}_{k}^{-}\right)
$$

where $z_{k}$ is actual measurement

The updated the Error covariance is given by

$$
P_{k}=\left(1-K_{k} H\right) P_{k}^{-}
$$


The Kalman filter requires 40 samples(10 minutes of data).

\section{ANN algorithm}

The Artificial Neural Network (ANN) algorithm which is proposed by that by Beltrami [10,11] is similar to that of the DART algorithm given by Mofjeld [4] (1997) in the sense that both the algorithms filters out the astronomical and meteorological surges recorded by a BPR by subtracting at each new time step the predicted pressure values from the observed pressure values and then examines the actual propagation of a Tsunami by comparing the amplitude of the filtered signal against a prescribed threshold value. Therefore, the ANN algorithm (similar to that of DART algorithm) also belongs to the category of the amplitude-discriminating ones. In order to update the prediction every $15 \mathrm{~s}$, ANN uses feed forward network shown in Figure 2 and 760 samples of data. The ANN algorithm proposed by [11] consists of a two adaptive-weight (feed-forward) network characterized by 4 input units plus bias, 6 hidden units plus bias and one output unit $\left(\mathrm{I}_{4} \mathrm{H}_{6} \mathrm{O}_{1}\right)$. The network's inputs consist of the same 10 -minute averages $\zeta$ of bottom pressure observations $\zeta$ as those used by the DART algorithm. These values are pre-processed so as to re-scale them linearly in the range [0;1]. The network function can be expressed as

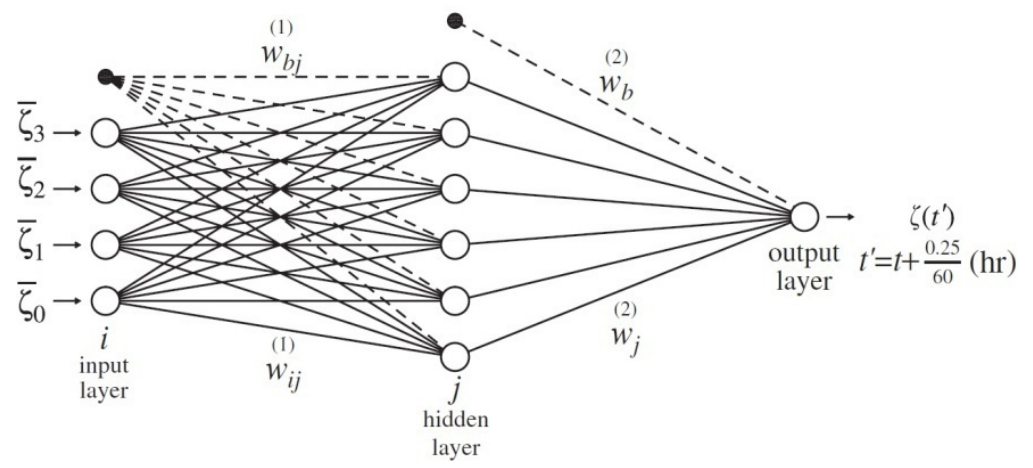

Fig. 2. Artificial Neural Network [11]

$$
\hat{\zeta}\left(t^{\prime}\right)=\tilde{g}\left\{w_{b}^{(2)}+\sum_{j=1}^{7} w_{j}^{(2)} g\left[w_{b j}^{(1)}+\sum_{i=0}^{3} w_{i j}^{(1)} \bar{\varsigma}\left(t^{\prime \prime}-i \Delta t\right)\right]\right\}
$$

Where

$t^{\prime}=t+0 \frac{0.25}{60} h, t^{\prime \prime}=t-\frac{n}{2 * 60} h$

and $\Delta \mathrm{t}=1 \mathrm{~h}\left(\mathrm{t}\right.$ is the actual time is an hour) also $\mathrm{w}_{\mathrm{ij}}{ }^{(1)}$ and $\mathrm{w}_{\mathrm{bj}}{ }^{(1)}$ are the adaptive weights connecting input units and bias to the hidden units , and $\mathrm{w}_{\mathrm{j}}{ }^{(2)}$ and $\mathrm{w}_{\mathrm{b}}{ }^{(1)}$ those connecting hidden units and bias to the output unit. Moreover, $\mathrm{g}(\cdot)$ and $\tilde{g}(\cdot)$ represent the hidden and output unit activation functions which are the logisticsigmoid and the linear activation functions respectively. Unlike the coefficients of the DART Algorithm, the adaptive weights of [11] result from the network's supervised learning. The adaptive weights (w) result from minimizing the error function chosen to express the difference between the calculated $\zeta^{\wedge}$ and the actually observed outputs $\zeta$.

\section{Comparison of Algorithms}

The predicted pressure values of DART, Kalman and ANN algorithms are compared with measured pressure during various stages of event. The Root Mean Square Error (RMSE), percentage error, correlation coefficient (r) and coefficient determination $\left(\mathrm{R}^{2}\right)$ are also computed at each stage.

\section{RESULTS AND DISCUSSION}

The DART, Kalman and ANN algorithms are implemented using MATLAB software (Figure 3). The differences between measured data and predicted data with the algorithms are computed (Figure 4(a), 4(b) \& 4(c)). The percentage of error is calculated respect to observed data sets shown in Table 1. A threshold of 0.03 $\mathrm{m}$ is applied on the differences and a Tsunami detection flag is generated shown in (Figure 5(a) \& 5(b)) and prediction algorithm test has been carried out using actually measured time series with three cases to calculate the algorithm performance. 


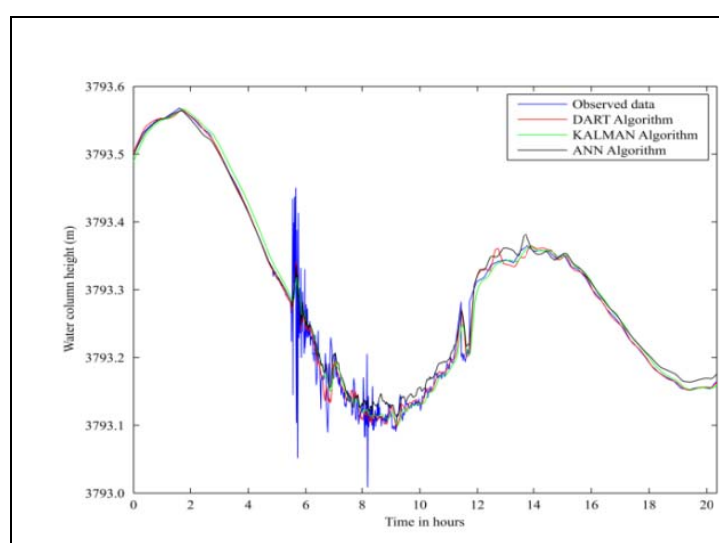

Fig. 3.Observed data and response of all three algorithms

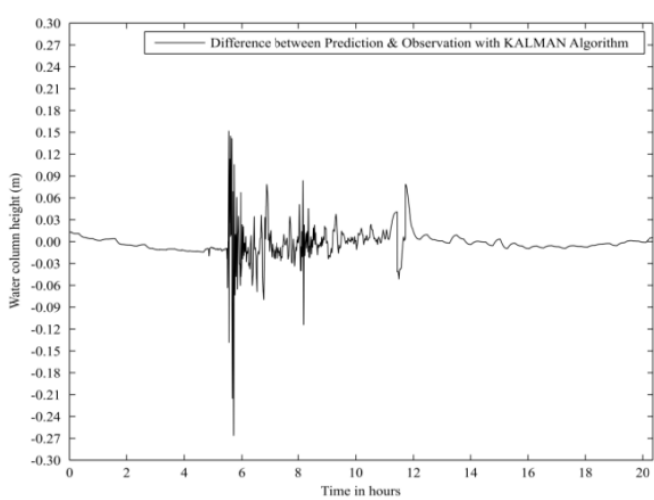

Fig. 4(b) Difference between prediction and observed with KALMAN Algorithm
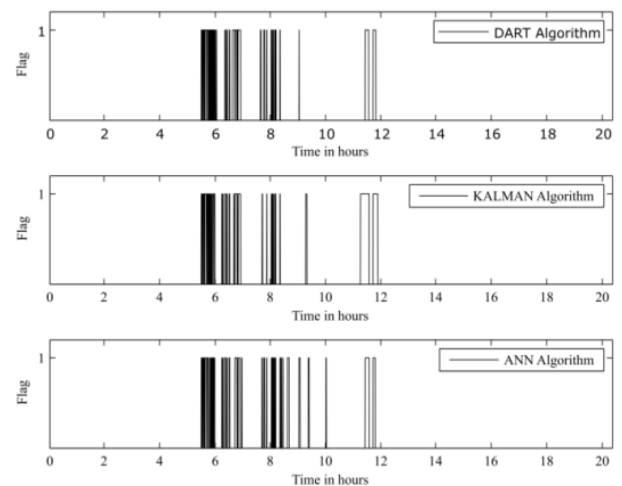

Fig.5(a) Tsunami detection flags

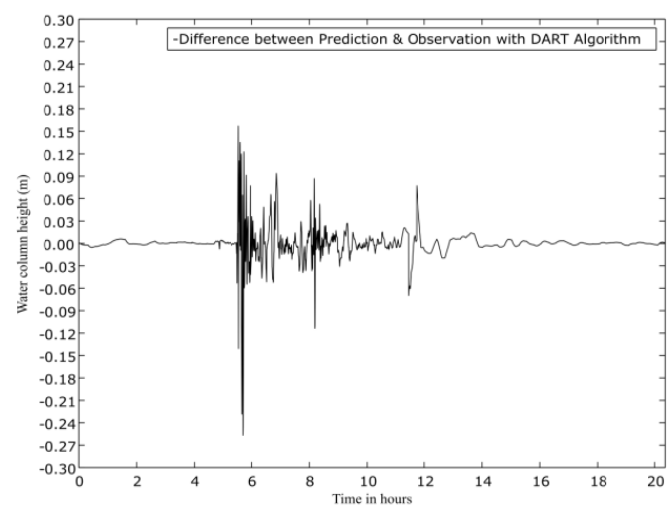

Fig. 4(a) Difference between prediction and observed with DART algorithm

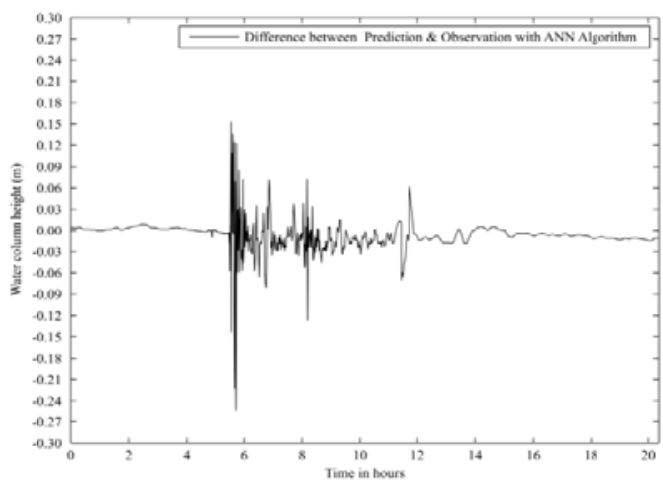

Fig. 4(c) Difference between prediction and observed with ANN Algorithm

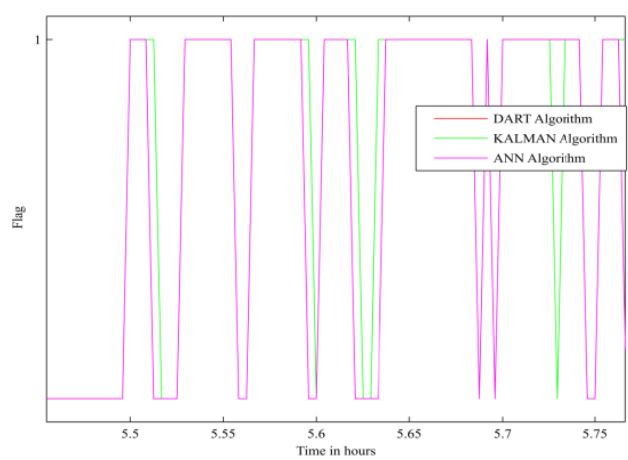

Fig. 5(b) combined Tsunami detection flag all three algorithms

TABLE 1. Comparison of Algorithms

\begin{tabular}{|l|c|c|c|}
\hline \multicolumn{1}{|c|}{ Algorithm } & Dart & Kalman & Ann \\
\hline No of samples required for valid prediction & 760 & 40 & 760 \\
\hline RMSE & $1.47492^{*} 10^{\wedge}-6$ & $1.898^{*} 10^{\wedge}-6$ & 0.016898 \\
\hline Avg. Error (\%) & $1.9231^{\wedge} 10^{\wedge}-4$ & $2.7805^{*} 10^{\wedge}-4$ & $1.6782 * 10^{\wedge}-4$ \\
\hline Coefficient determination & 0.99608 & 0.99539 & 0.99634 \\
\hline Correlation coefficient & 0.99199 & 0.99072 & 0.99272 \\
\hline Delay in detection with respect to DART (sec.) & 0 & $<15 \mathrm{sec}$ & $<15 \mathrm{sec}$ \\
\hline
\end{tabular}




\section{CONCLUSION}

All the algorithms detect to the event signal at the same time and Kalman algorithm takes more time to fall than other two algorithms. The average percentage of error is lower in ANN. The correlation coefficient has higher strength in forward modeling which is positive (0-1).

\section{ACKNOWLEDGEMENT}

The authors are thankful director NIOT for supporting the study and staff of Ocean Electronics group of NIOT for their encouragement and support.

\section{REFERENCE}

[1] Eble, M.C., and F.I. González (1991): Deep-ocean bottom pressure measurements in the northeast Pacific. J. Atmos. Ocean. Tech., 8(2), 221-233.

[2] Milburn, H.B., A.I. Nakamura, and F.I. Gonzalez (1996): Real time Tsunami reporting from the deep ocean. Proceedings of the Oceans 96 MTS/IEEE Conference. 23-26 September 1996, Fort Lauderdale, FL, 390-394.

[3] NOAA data archive site http://www.ndbc.noaa.gov/dart.shtml

[4] H.O.Mofjeld, Tsunami Detection Algorithm, http://nctr.pmel.noaa.gov/ tda_documentation.html

[5] Sivacoumar, R., Bhanarkar, A.D., Goyal, S.K., Gadkari, S.K., Aggarwal, A.L., 2001. Air pollution modeling for an industrial complex and model performance evaluation. Environmental Pollution 111, 471-477

[6] Tolga Elbir, Comparison of model predictions with the data of an urban air quality monitoring network in Izmir, Turkey, Atmospheric Environment 37 (2003) 2149-2157.

[7] Mohinder S. Grewal, Angus P. Andrews (2001): Kalman Filtering: Theory and Practice Using MATLAB, John Wiley \& Sons

[8] Sorenson, Harold W. (1985): Kalman filtering: theory and application, New York.

[9] G.A. Ramadass, N Vedachalam, Tata Sudhakar, R Ramesh, VBN Jyothi, NB Prashanth, MA Atmanand, A Study of the algorithms for the detection of Tsunmai using an Ocean Bottom pressure recorder Marine Technology Society Journal, Vol. 48, No.1, Jan/Feb 2014, page $76-83$.

[10] Gian Mario Beltrami, An ANN algorithm for automatic, real-time Tsunami detection in deep-sea level measurements, Ocean Engineering 35 (2008) 572-587

[11] Gian Mario Beltrami, Marcello Di Risio and Paolo De Girolamo, Algorithms for Automatic, Real-Time Tsunami Detection in Sea Level Measurements, DISAT-LIAM - Universit`a di L'Aquila Italy

\section{AUTHORS PROFILE}

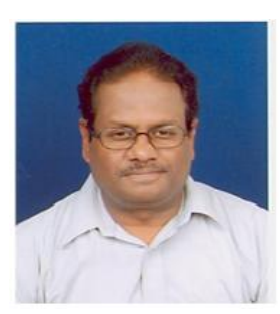

Tata Sudhakar, received Master degree in Electronics and Control from Sathyabama University, Chennai. Has experience of 30 years in different Oceanographic Institutions. Received National Geo Science Award for excellence of the Ministry of Mines, Govt. of India in the category of Disaster Management for the contributions to the Establishment of Indian Tsunami Warning system. Presently heading technology development group at National Institute of Ocean Technology, Chennai, India. He has filled four patents and has about 15 research papers.

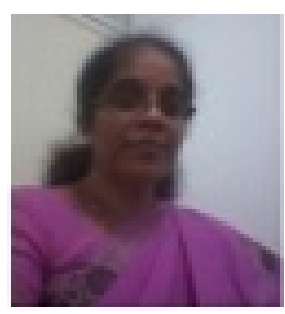

S.D.Suryakala, an Engineering Graduate in Electronics and Communication Engineering from Manipal Institute of Technology, Manipal, Did Masters MS in Electronics \& Control from BITS, Pilani \& M.S (By Research) from Anna University, Chennai \& completed PhD in Software Agents for Communication with a total experience of 24 years which includes teaching as well as research. At present, She is associated with Department of Electronics \& Tele communication Engg., SNGCE, KOLENCHERY. Sponsored projects (NRSC\& DRDO), more than 100 publications in refereed conferences and journals added credit in career research area is in wireless communication \& software Agents .Member of professional Society like IEEE, ISTE, and Fellow member of IETE \& IE. 